\title{
Listeriosis Knowledge and Attitude among Pregnant Women Attending a Tertiary Health Institution, South Western Nigeria
}

\author{
Emelda E. Chukwu ${ }^{1}$, Francisca 0. Nwaokorie ${ }^{2}$ \\ ${ }^{1}$ Center for Infectious Disease Research, Microbiology Department of the Nigerian Institute of Medical Research, \\ Yaba, Nigeria \\ ${ }^{2}$ Department of Medical Laboratory Sciences, College of Medicine, University of Lagos, Lagos, Nigeria \\ Email: *emeldachukwu123@gmail.com
}

How to cite this paper: Chukwu, E.E. and Nwaokorie, F.O. (2020) Listeriosis Knowledge and Attitude among Pregnant Women Attending a Tertiary Health Institution, South Western Nigeria. Advances in Infectious Diseases, 10, 64-75.

https://doi.org/10.4236/aid.2020.102006

Received: March 20, 2020

Accepted: April 24, 2020

Published: April 27, 2020

Copyright $\odot 2020$ by author(s) and Scientific Research Publishing Inc. This work is licensed under the Creative Commons Attribution International License (CC BY 4.0).

http://creativecommons.org/licenses/by/4.0/

(c) (i) Open Access

\begin{abstract}
Background: Listeriosis affects immunosuppressed individual's especially pregnant women. Maternal infections are usually mild for the woman, but may have devastating effects on the unborn child, including miscarriage, stillbirth, preterm labour and serious neonatal illness. WHO recommends that pregnant women should be educated to avoid foods with high risk of contamination. This study seeks to evaluate knowledge and practices predisposing to listeria infections during pregnancy. Methodology: This is a crosssectional study on pregnant women, attending the antenatal clinic of Lagos University Teaching Hospital (LUTH) using semi structured questionnaires. The knowledge score of participants was collated and analyzed using SPSS version 26. Results: The mean age of the participants was $32.07 \pm 5.6$ years. Forty-three (30.7\%) women have had previous miscarriages with the mean no of miscarriage of 1.54. Out of 147 participants, only 20 (13.6\%) admitted having heard of listeriosis while $127(86.4 \%)$ had never heard of listeriosis and none of the participants has ever been tested for listeriosis. The Overall knowledge score was poor, and this was irrespective of age and duration of pregnancy. However, women with graduate and/or postgraduate degrees were more likely to have heard of Listeriosis $\left(\mathrm{X}^{2}=10.88, \mathrm{P}=0.028\right)$. Conclusion: Our study shows a low level of knowledge about this food-borne illness, which can lead to severe illnesses in pregnant women and their unborn child. It is necessarily to educate pregnant women on the risk of listeriosis. This would be a key factor in creating and implementing accurate measures of prevention and control.
\end{abstract}

\section{Keywords}

Listeriosis, Listeria monocytogenes, Pregnant Women, Fetal Death, Nigeria 


\section{Introduction}

Listeria monocytogenes is an emerging food borne pathogen capable of causing serious invasive disease with mortality rates ranging between $80 \%$ and $99 \%$ primarily in neonates, immunocompromised adults and pregnant women [1] [2]. It was estimated that $99 \%$ of listeriosis cases occur due to food borne transmission of the bacteria [3]. In 2011, listeriosis led to by far the most food-related deaths caused by bacteria in the European Union, much more than salmonellosis [4]. In humans, the average case-fatality rate of listeriosis is between $20 \%$ and $30 \%$ even with adequate antimicrobial treatments [5] [6]. Invasive listeriosis is characterized by high mortality and disproportionately affects immunosuppressed individual's especially pregnant women. Typical sources of ingestion by humans are raw foods of animal and soil origin, such as raw milk and dairy products, fresh meat, fruit, vegetables and seafood [7] [8].

World Health Organisation (WHO) and Food and Agriculture Organisation (FAO) have published an international quantitative risk assessment of Listeria in ready-to-eat foods titled "Guidelines on the Application of General Principles of Food Hygiene to the Control of Listeria monocytogenes in Foods". This guideline includes microbiological criteria i.e. maximum limits for the presence of L. monocytogenes in foods [9]. WHO warns that pregnant women, the elderly or individuals with a weakened immune system, such as people with immunocompromised status due to HIV/AIDS, leukaemia, cancer, kidney transplant and steroid therapy, are at greatest risk of severe listeriosis and should avoid high risk foods. The foods flagged as high risk include deli meat and ready-to-eat meat products (such as cooked, cured and/or fermented meats and sausages), soft cheeses and cold smoked fishery products [9].

Infection in pregnant women may cause moderate maternal illness but can be extremely serious for the foetus leading to miscarriage, stillbirth, preterm labour and serious neonatal illness [6]. A pregnant woman may abort her foetus, or the child may be born seriously ill. Despite an increasing rate of listeriosis reported in several European countries in recent years [10], and other outbreaks in the United States [11], Canada [12] [13] and China [14], the occurrence and prevalence of listeriosis in Nigeria is hardly reported. This is possibly due to lack of a comprehensive surveillance system for food-borne pathogens [15]. However, various reports have established Listeria spp. in dairy products, meat and poultry [16], ready to eat vegetables [17], smoked and raw fish [18] [19] as well as in farm animals and abattoirs [16] [20] in Nigeria. The first case of neonatal listeriosis in Nigeria was reported by Onyemelukwe and Lawande [21] when they isolated L. monocytogenes of the same serotype from a 2-day old neonate who developed Listeria meningitis after contracting the organism from the mother. Subsequently, Shindang et al. [22] reported L. monocytogenes prevalence of 8.04\% from blood and placental samples from spontaneous abortion cases in Jos, Nigeria.

The level of knowledge on listeriosis in pregnant women has not been assessed 
in Nigeria. Since pregnancy-associated listeriosis causes potentially fatal consequences, food safety knowledge is paramount during pregnancy. Therefore, there is need to ascertain the level of knowledge of pregnant women in Nigeria on listeriosis risk, mode of transmission and food safety practices during pregnancy. This would be a key factor in creating and implementing accurate measures of control, prevention and protection.

\section{Methodology}

Study site: The study site was the Lagos University Teaching Hospital (LUTH). LUTH is one of the largest Teaching Hospital in Nigeria with over 761 beds and housing the College of Medicine of the University of Lagos which trains hundreds of Medical, Dental, Pharmacy and other Science Students. All pregnant women attending the antenatal clinic during the period of May to August 2019 who gave their consent were included in this study.

Study design: This was a cross-sectional study carried out from May to August 2019. A semi structured questionnaire of 35 questions with predefined answers were developed and applied to 147 pregnant women, from different demographic regions in Lagos attending the antenatal clinic of Lagos University Teaching Hospital. Pregnant women were asked to participate by completing a self-administered questionnaire based on the Knowledge of listeriosis and standard food safety practices and recommendations for pregnant women to avoid Listeria infection. Written consents were obtained, after informing about the topic of the questionnaire. The answers to 12 questions were used to calculate the score of participants. The knowledge level was scored $0-4$ as poor, 5 - 8 as fair and $9-12$ as good. The association between different socio-demographic variables and Listeria knowledge, and related food practices, were investigated using bivariate and multivariate analysis. Analysis was done using SPSS version 26.

Statistical Analysis: Both parametric and nonparametric procedures were used to assess the data. All summed scores were assessed for normality using normality plots. Normally distributed data were assessed using parametric Student's $t$ tests. If data were not normally distributed, nonparametric chi-squared tests were used to compare differences between different educational groups. Fisher's exact chi-square tests were used to detect differences for item responses within the scored L. monocytogenes knowledge questions. Statistical procedures were completed using IBM SPSS Statistics (version 26, IBM, Chicago, IL). Significance was declared if the p-value was less than 0.05 .

\section{Results}

The mean age of the participants was $32.07 \pm 5.6$ years. Most of the women in our study were aged between $26-30$ years (30.6\%) and $31-35$ years $(26.5 \%)$, with at least a bachelor's degree (76.8\%) and in the last trimester of pregnancy (72.8\%) Table 1. Forty-five (30.6\%) respondents have had previous miscarriages 
Table 1. Socio-demographic characteristic of the participants.

\begin{tabular}{|c|c|}
\hline Variables & Respondents $(n=147)$ \\
\hline \multicolumn{2}{|l|}{ Age } \\
\hline $20-25$ & $20(13.6)$ \\
\hline $26-30$ & $45(30.6)$ \\
\hline $31-35$ & $39(26.5)$ \\
\hline $36-40$ & $33(22.4)$ \\
\hline $41-45$ & $10(6.8)$ \\
\hline \multicolumn{2}{|l|}{ Degree } \\
\hline No schooling completed & $0(0)$ \\
\hline Primary education & $6(4.1)$ \\
\hline Secondary education & $17(11.6)$ \\
\hline Technical/Vocational training & $11(7.5)$ \\
\hline Bachelor's degree & $94(63.9)$ \\
\hline Master's degree & $19(12.9)$ \\
\hline \multicolumn{2}{|l|}{ Duration of pregnancy } \\
\hline $1^{\text {st }}$ trimester & $3(2.0)$ \\
\hline $2^{\text {nd }}$ trimester & $37(25.2)$ \\
\hline $3^{\text {rd }}$ trimester & $107(72.8)$ \\
\hline \multicolumn{2}{|l|}{ Recent antibiotic therapy } \\
\hline Yes & $8(5.4)$ \\
\hline No & $139(94.5$ \\
\hline \multicolumn{2}{|l|}{ Previous Miscarriages } \\
\hline Yes & $45(30.6)$ \\
\hline No & $102(69.4)$ \\
\hline \multicolumn{2}{|l|}{ Number of miscarriages } \\
\hline One & $29(19.7)$ \\
\hline Two & $8(5.4)$ \\
\hline Three & $7(4.8)$ \\
\hline Five & $1(0.7)$ \\
\hline None & $102(69.4)$ \\
\hline \multicolumn{2}{|l|}{ Have you heard of Listeriosis before? } \\
\hline Yes & $20(13.6 \%)$ \\
\hline No & $127(86.4 \%)$ \\
\hline \multicolumn{2}{|l|}{ Knowledge score } \\
\hline Poor & $121(82.3)$ \\
\hline Fair & $22(15.0)$ \\
\hline Good & $4(2.7)$ \\
\hline Mean age of participants \pm Standard deviation (STD) & $32.07 \pm 5.65$ \\
\hline Mean duration of Pregnancy in weeks \pm STD & $29.12 \pm 7.54$ \\
\hline Mean Knowledge score \pm STD & $1.71 \pm 2.7$ \\
\hline
\end{tabular}


with the mean number of miscarriages as 1.54. Respondents that are 36 years and above were more likely to have had a previous miscarriage $\left(\mathrm{X}^{2}=10.29, \mathrm{P}=\right.$ 0.036).

Out of 147 participants, only 20 (13.6\%) admitted having heard of listeriosis while $86.4 \%$ had never heard of listeriosis and none of the participants has ever been tested for listeriosis. Of the $13.6 \%$ who have heard of listeriosis, majority of them sourced their knowledge from the internet while only two (1.4\%) mentioned that they obtained their information from health/pregnancy classes (Figure 1).

Using the knowledge assessment score, none of the participants managed to respond with full correctness on general knowledge on the topic of listeriosis. However, $82.3 \%$ had poor knowledge, $15.0 \%$ had fair knowledge while $2.7 \%$ of the participants had good knowledge of the topic. Respondents with master's degree had higher level of knowledge, although this was not significant $\left(\mathrm{X}^{2}=\right.$ $10.02, \mathrm{p}=0.264$ ) Table 2. However, comparison of respondents with bachelor's degree/postgraduate degree versus no schooling/ primary or secondary education showed that women with graduate and/or postgraduate degrees were more likely to have heard of Listeriosis $\left(\mathrm{X}^{2}=10.88, \mathrm{P}=0.028\right)$.

Ninety-seven (66\%) of the pregnant women were not aware that they should avoid eating food with a high risk of contamination with Listeria e.g. hot dog, meat spread, cheese, unpasteurized raw milk (Fura) etc and $78.2 \%$ are oblivious of the fact that Listeriosis can be passed to their unborn baby during pregnancy (Figure 2).

Majority of the respondents were not sure of the cause of Listeriosis and only $13.8 \%$ of the respondents correctly identified the bacteria Listeria monocytogenes as the cause of the illness while $8.2 \%$ recognized exposure to domestic animals as a predisposing factor to Listeriosis (Figure 3 ). Less than a third of the

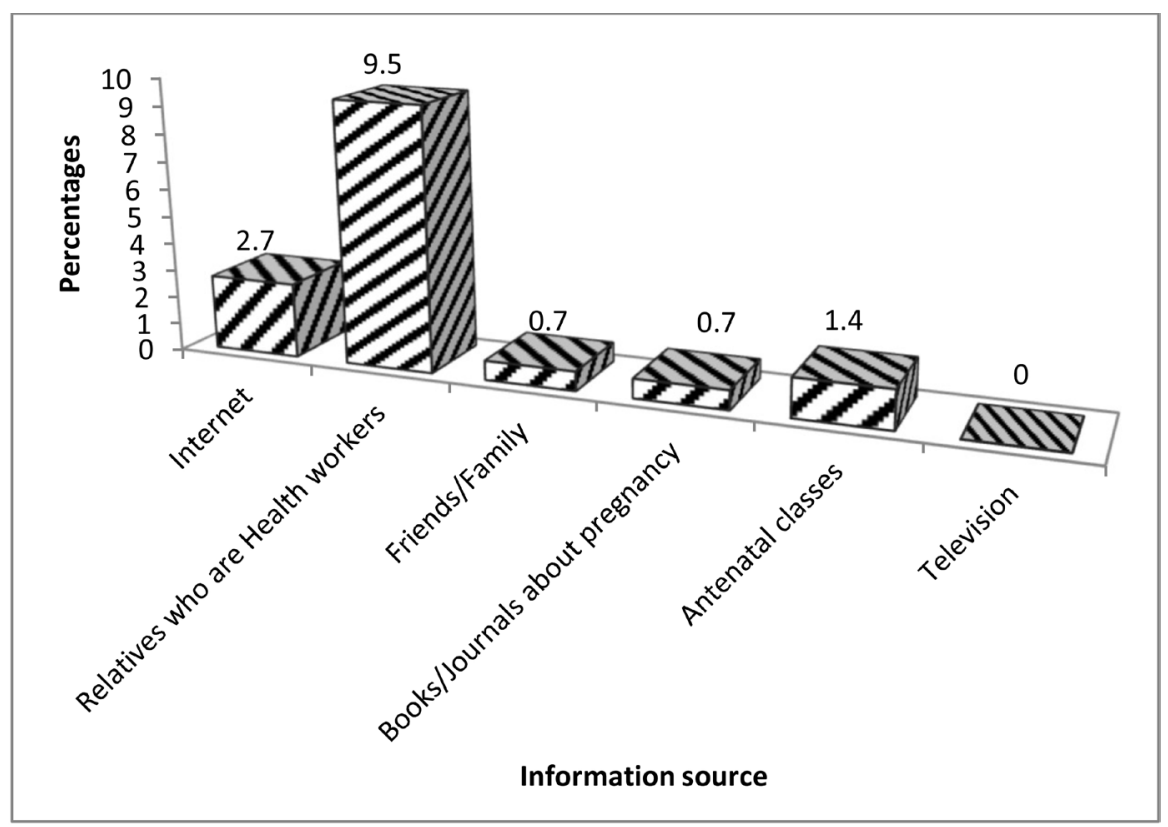

Figure 1. Source of information on Listeriosis. 
Table 2. Distribution of knowledge score across the different variables.

\begin{tabular}{|c|c|c|c|c|c|c|}
\hline & \multirow{2}{*}{ Variable } & \multicolumn{3}{|c|}{ Knowledge Score } & \multirow{2}{*}{$\begin{array}{l}\text { Chi-squared } \\
\qquad\left(\mathrm{X}^{2}\right)\end{array}$} & \multirow{2}{*}{ P-value } \\
\hline & & Poor (\%) & Fair (\%) & Good (\%) & & \\
\hline \multirow[t]{6}{*}{ Age } & $20-25$ & $17(85.0)$ & $3(15.0)$ & $0(0)$ & 4.89 & 0.769 \\
\hline & $26-30$ & $36(80.0)$ & $6(13.3)$ & $3(6.7)$ & & \\
\hline & $31-35$ & $32(82.1)$ & $6(15.4)$ & $1(2.6)$ & & \\
\hline & $36-40$ & $27(81.8)$ & $6(15.4)$ & $1(2.6)$ & & \\
\hline & $41-45$ & $9(90.0)$ & $1(10.0)$ & $0(0)$ & & \\
\hline & Total & $121(82.3)$ & $22(15.0)$ & $4(2.7)$ & & \\
\hline \multirow[t]{5}{*}{ Degree } & Primary education & $6(100)$ & $0(0)$ & $0(0)$ & 10.02 & 0.264 \\
\hline & Secondary education & $15(88.2)$ & $2(11.8)$ & $0(0)$ & & \\
\hline & $\begin{array}{c}\text { Technical/Vocational } \\
\text { training }\end{array}$ & $9(81.8)$ & $1(9.1)$ & $1(9.1)$ & & \\
\hline & Bachelor's degree & $78(83.0)$ & $15(16.0)$ & $1(1.1)$ & & \\
\hline & Master's degree & $13(68.4)$ & $4(21.1)$ & $2(10.5)$ & & \\
\hline \multirow[t]{3}{*}{ Trimester } & $1^{\text {st }}$ trimester & $2(66.7)$ & $1(33.3)$ & $0(0)$ & 2.81 & 0.591 \\
\hline & $2^{\text {nd }}$ trimester & $28(75.7)$ & $8(21.6)$ & $1(2.7)$ & & \\
\hline & $3^{\text {rd }}$ trimester & $91(85.0)$ & $13(12.1)$ & $3(2.8)$ & & \\
\hline
\end{tabular}

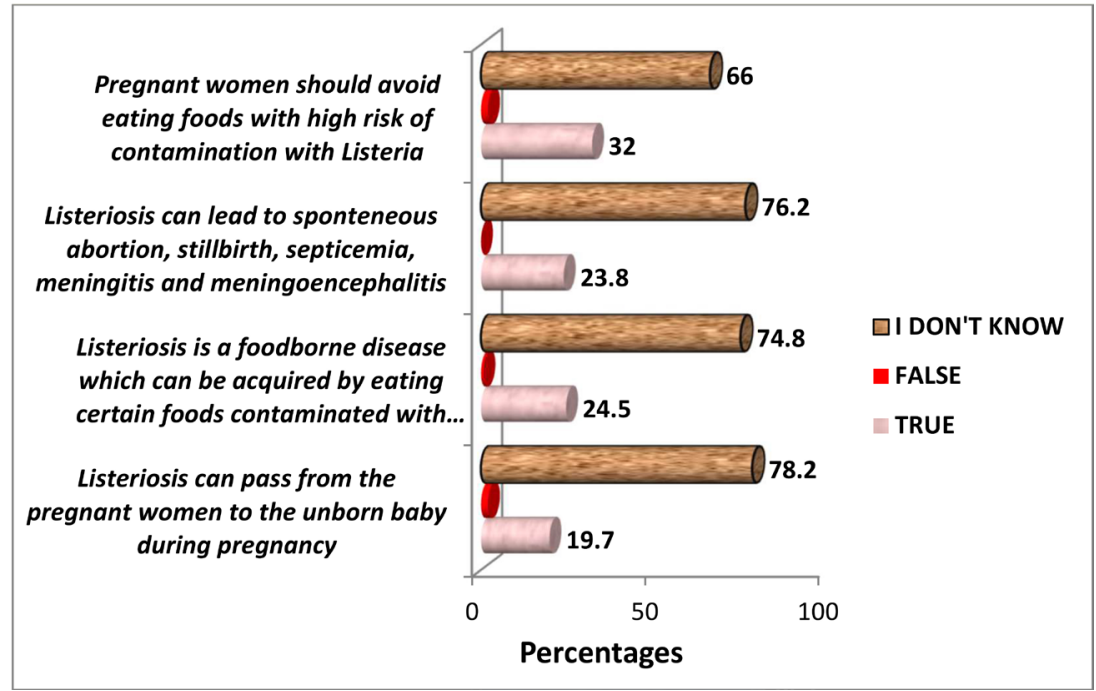

Figure 2. Responses to some of the Knowledge questions.

respondents $(17.7 \%$ and $22.1 \%)$ reported cough and catarrh symptoms respectively while $4.8 \%$ of the women have had fever more than five days. On the average, $90.6 \%$ of the respondents were not sure of the actual symptoms of listeriosis and a few of them (8.8\%) assumed diarrhoea, nausea and vomiting to be the symptoms of listeriosis (Figure 4).

Majority of the participants (92.5\%) preferred homemade meals. However, some of them confessed to sometimes eat at the restaurants (15.6\%), roadside 


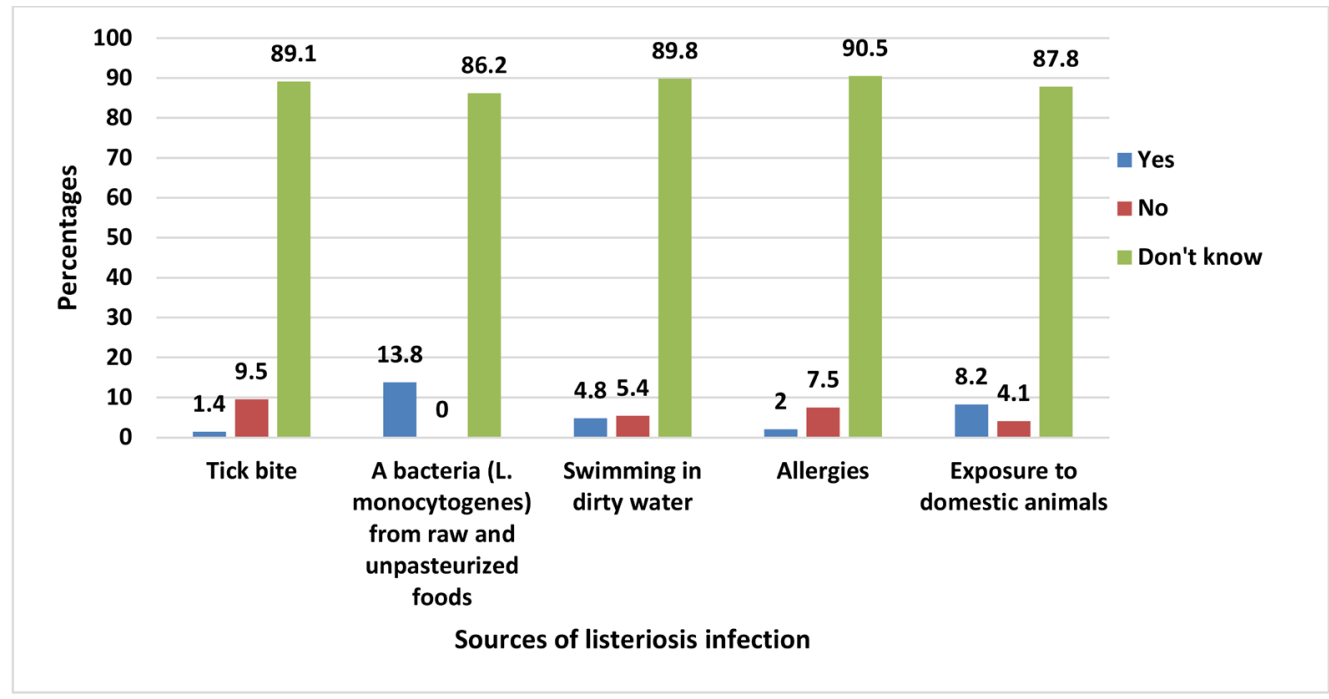

Figure 3. Responses to sources of Listeriosis infection.

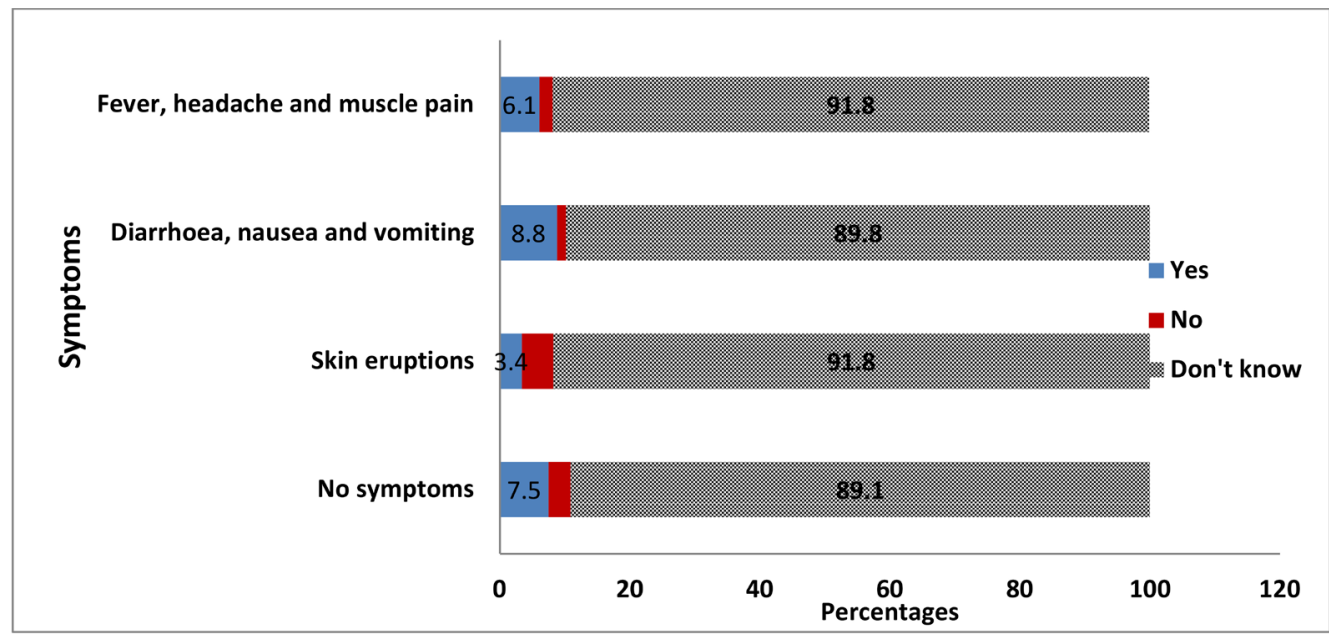

Figure 4. Perceived symptoms of listeriosis.

(10.9\%) and Canteens (9.5\%).

Twenty-two (15.0\%) of the women admitted having been exposed to domestic animals. The most commonly implicated animals are dogs (45.5\%), poultry (36.4\%) and Cats (13.6\%). Other animals listed are cows (2.1\%) and goats (2.1\%).

\section{Discussion}

Pregnant women and their new-borns are particularly susceptible to severe listeriosis and simple precautions during pregnancy have been shown to prevent listeriosis [2]. It is however quite unfortunate that many women are unaware of these precautions and listeriosis education is often omitted from prenatal care. In our study, $86.4 \%$ of the respondents had never heard of listeriosis and none of the participants has ever been tested for listeriosis. This contrast with a previous study in Western Australia where 89\% of the pregnant women have heard of listeriosis [23]. The authors noted that $11 \%$ who had no knowledge were younger 
women in their first pregnancy and women with lower educational qualification. On the contrary, our findings recorded no significant difference in the knowledge level across the different levels of education. A study by Bondarianzadeh et al. [24] on 586 pregnant women in New South Wales, reported that $66 \%$ of respondents knew listeriosis is an illness that is transmitted by contaminated food. More so, a high percentage of the respondents in that study acknowledged that some food-borne illnesses could be dangerous for their unborn child. Regrettably in our present study, a significant percentage of the women were oblivious of the fact that Listeriosis can be passed to their unborn baby during pregnancy. The poor level of knowledge recorded in this study is a source of concern considering that $66 \%$ of the pregnant women were not even aware of foods with a high risk of contamination e.g. hot dog, meat spread, cheese, unpasteurized raw milk (Fura). In a qualitative study using focus groups of pregnant women in British Columbia, participants reported that food safety and the risk of listeriosis were important to them during pregnancy; however, their knowledge of highrisk foods and safe food practices was also limited [25].

Out of the $13.6 \%$ who admitted having heard of listeriosis, majority of their knowledge was sourced from the internet and relatives while only two (1.4\%) women stated that they obtained their information from antenatal classes. This finding contrasts with the report of a multi-state survey of pregnant women in the US where about a half of the respondents reported hearing about listeriosis from a medical professional [26]. On the other hand, a knowledge, attitude and practice study on medical professionals in the US noted that there are gaps in knowledge and a self-declared lack of understanding about Listeria monocytogenes [27]. Similar pattern was also reported by a study in British Columbia [28]. This low level of knowledge of listeriosis among medical practitioners may be contributing to the lack of antenatal education. Furthermore, a focus group research with physicians revealed that obstetricians are less likely to provide patients at high risk with information on listeriosis prevention since they deem foodborne illness as less important than other disease conditions, such as heart health, smoking, and drug and alcohol use [29]. Similarly, a qualitative study in the US evaluated the food safety practices during pregnancy and suggested that educational efforts should target both healthcare providers as well as the pregnant women [30].

Using the knowledge score, none of the participants managed to respond correctly to all the general knowledge questions on the topic of listeriosis and very few $(2.7 \%)$ of them were well informed. This poor knowledge score is similar to a much earlier study in the United States where $82 \%$ of the participants in a national survey had poor knowledge [26]. In addition to the overall poor knowledge about listeriosis among pregnant women in LUTH, we were unable to detect any trends in knowledge levels by age, educational levels and pregnancy duration $\left(\mathrm{X}^{2}=10.02, \mathrm{p}=0.264\right)$.

Although majority of our respondents possessed at least a bachelor's degree, 
this did not reflect in any significant improvement in knowledge level among these group of women. However, comparison of respondents with bachelor's degree/postgraduate degree versus no schooling/ primary or secondary education showed that women with graduate and/or postgraduate degrees were more likely to have heard of Listeriosis $\left(\mathrm{X}^{2}=10.88, \mathrm{P}=0.028\right)$

With regards to preventive behaviors, it was re-assuring to note that $92.5 \%$ of the women preferred and ultimately consume homemade meals. It is pertinent to note however, that even though most respondents avoided patronizing canteens, roadside and ready-to-eat food, they were unaware of the risk associated with these practices. Therefore, effort should be made towards encouraging the pregnant women to prepare their own meals and ensure proper food handling. Unfortunately, $8.8 \%$ of the respondents erroneously assumed that Listeriosis will present with nausea, vomiting and diarrhoea when in the actual sense, it is a febrile illness and can sometimes present with flu-like symptoms

Listeriosis is relatively rare, but can have mortality rates as high as $30 \%$, especially among vulnerable groups such including pregnant women [31]. For this reason, most western countries have developed set-down policies and guidelines to monitor and control L. monocytogenes in foods as well as educate pregnant women on the need to avoid high risk foods. Although there is a dearth of literature on the incidence of Listeriosis in Nigeria, several studies have reported massive contamination of dairy products, meat, poultry foods and environmental samples in Nigeria. This points to a possibility of clinical cases which may go un-detected and un-reported. In 1999, Center for Disease Control produced a brochure for pregnant women, entitled "what you can do to keep germs from harming you and your baby", that included information on listeria. Taking this further, the United States Department of Agriculture (USDA) in 2001 collaborated with other agencies to produce a patient education sheet, "Listeriosis and pregnancy: what is your risk?", which targeted both pregnant women and their healthcare providers [26]. Unfortunately, such interventions do not exist in $\mathrm{Ni}$ geria and some other African countries.

This study had some limitations. The use of voluntary participation led to some of the pregnant women declining to participate since they felt that they were not conversant with the topic. The small sample size used in this study limits our ability to generalize our findings. However, the use of knowledge scoring allowed for mitigation of bias from self-grading thereby enabling proper knowledge assessment. Improved education of these pregnant women regarding the risk and sources of listeriosis in pregnancy is urgently required to avert future outbreaks.

\section{Conclusion}

Our study shows an alarming low level of knowledge about this food-borne illness which may lead to an increased risk for pregnant women to acquire listeriosis. As long as serious prevention and control measures are not being imple- 
mented, outbreaks or sporadic cases may appear at any moment. Point of care screening for pregnant women during antenatal visits should also be considered and may go a long way in ensuring early detection and treatment. Moreover, we consider it extremely necessarily to educate pregnant women to change attitudes, improve knowledge in order to reduce the risk of this infection. Prenatal care providers should provide full information on this topic and counsel on food practices during pregnancy. Also, national awareness campaigns can be targeted at promoting adequate prevention methods.

\section{Acknowledgements}

The authors wish to acknowledge Miss Faith Nwamaka, Miss Francisca Udegbe and Mr Olumuyiwa Olukoya of the Department of Medical Laboratory Sciences, College of Medicine of the University of Lagos for their secretarial assistance.

\section{Ethics Approval and Consent to Participate}

The study protocol as well as other study materials were reviewed and approved by the Ethical review committee and research Board of Lagos University Teaching hospital (NHREC: 19/12/2008a). Participants were required to sign an informed consent form while information obtained from the participants were treated as confidential and personal identifiers were not used.

\section{Author's Contribution}

This work was done in collaboration between both authors. The first author (CEE) designed the study, developed the questionnaire, collected data, wrote the draft manuscript and corresponded with the journal. The second authors (FON) participated in the development of the data collection tool and statistical analysis. Both authors contributed to the literature searches and approved the final manuscript.

\section{Conflicts of Interest}

The authors declare no conflicts of interest regarding the publication of this paper.

\section{References}

[1] Parihar, V.S., Lopez-Valladares, G., Danielsson-Tham, M.L., Peiris, I., Helmersson, S., Unemo, M., et al. (2008) Characterization of Human Invasive Isolates of Listeria monocytogenes in Sweden 1986-2007. Foodborne Pathogens and Diseases, 5, 755-761. https://doi.org/10.1089/fpd.2008.0123

[2] McNeill, C., Sisson, W. and Jarrett, A. (2017) Listeriosis: A Resurfacing Menace. The Journal for Nurse Practitioners, 13, 647-654. https://doi.org/10.1016/j.nurpra.2017.09.014

[3] Scallan, E., Hoekstra, R.M., Angulo, F.J., Tauxe, R.V., Widdowson, M.A., Roy, S.L., et al. (2011) Foodborne Illness Acquired in the United States-Major Pathogens. Emerging Infectious Diseases, 17, 7-15. https://doi.org/10.3201/eid1701.P11101 
[4] European Food Safety Authority (EFSA) and European Centre for Disease Prevention and Control-ECDC (2013) The European Union Summary Report on Trends and Sources of Zoonoses, Zoonotic Agents and Food-Borne Outbreaks in 2011. European Food Safety Authority Journal, 11, 3129. https://doi.org/10.2903/j.efsa.2013.3129

[5] Swaminathan, B. and Gerner-Smidt, P. (2007) The Epidemiology of Human Listeriosis. Microbes and Infection, 9, 1236-1243. https://doi.org/10.1016/j.micinf.2007.05.011

[6] Pucci, L., Massacesi, M. and Liuzzi, G. (2018) Clinical Management of Women with Listeriosis Risk during Pregnancy: A Review of National Guidelines. Expert Review of Anti-Infective Therapy, 16, 13-21. https://doi.org/10.1080/14787210.2018.1417837

[7] Fenlon, D.R., Wilson, J. and Donachie, W. (1996) The Incidence and Level of Listeria monocytogenes Contamination of Food Sources at Primary Production and Initial Processing. Journal of Applied Bacteriology, 81, 641-650. https://doi.org/10.1111/j.1365-2672.1996.tb01966.x

[8] Wagner, M., Auer, B., Trittremmel, C., Hein, I. and Schoder, D. (2007) Survey on the Listeria Contamination of Ready-to-Eat Food Products and Household Environments in Vienna, Austria. Zoonoses and Public Health, 54, 16-22. https://doi.org/10.1111/j.1863-2378.2007.00982.x

[9] World Health Organization (2018). https://www.who.int/news-room/fact-sheets/detail/listeriosis

[10] Allerberger, F. and Wagner, M. (2010) Listeriosis: A Resurgent Foodborne Infection. Clinical Microbiology and Infection, 16, 16-23. https://doi.org/10.1111/j.1469-0691.2009.03109.x

[11] Cartwright, E.J., Jackson, K.A., Johnson, S.D., Graves, L.M., Silk, B.J. and Mahon, B.E. (2013) Listeriosis Outbreaks and Associated Food Vehicles, United States, 1998-2008. Emerging Infectious Diseases, 19, 1-9. https://doi.org/10.3201/eid1901.120393

[12] Taillefer, C., Boucher, M., Laferrière, C. and Morin, L. (2010) Perinatal Listeriosis: Canada's 2008 Outbreaks. Journal of Obstetrics and Gynaecology Canada, 32, 45-48. https://doi.org/10.1016/S1701-2163(16)34403-6

[13] Clark, C.G., Farber, J., Pagotto, F., Ciampa, N., Doré, K., Nadon, C., Bernard, K. and Ng, L.K. (2010) Surveillance for Listeria monocytogenes and Listeriosis, 1995-2004. Epidemiology and Infection, 138, 559-572. https://doi.org/10.1017/S0950268809990914

[14] Wang, H.L., Ghanem, K.G., Wang, P., Yang, S. and Li, T.S. (2012) Listeriosis at a Tertiary Care Hospital in Beijing, China: High Prevalence of Non-Clustered Healthcare-Associated Cases among Adult Patients. Clinical Infectious Diseases, 56, 666676. https://doi.org/10.1093/cid/cis943

[15] Nwaiwu, O. (2015) An Overview of Listeria Species in Nigeria. International Food Research Journal, 22, 455-464.

[16] Mawak, J.D., Onubogu, T.M., Chukwu, O.O.C., Ngulukun, S.S. and Muhammad, M.J. (2006) The Occurrence of Listeria monocytogenes in Faeces of Domesticated Poultry. Bio-Research, 4, 109-112. https://doi.org/10.4314/br.v4i2.117362

[17] Ajayeoba, T.A., Atanda, O.O., Obadina, A.O., Bankole, M.O. and Adelowo, O.O. (2016) The Incidence and Distribution of Listeria monocytogenes in Ready-to-Eat Vegetables in South-Western Nigeria. Food Science \& Nutrition, 4, 59-66. https://doi.org/10.1002/fsn3.263 
[18] Salihu, M.D., Junaidu, A.U., Manga, S.B., Gulumbe, M.L., Magaji, A.A., Ahmed, A., Adamu, A.Y., Shittu, A. and Balarabe, I. (2008) Occurrence of Listeria monocytogenes in Smoked Fish in Sokoto, Nigeria. African Journal of Biotechnology, 7, 3082-3084.

[19] Lennox, J.A., Etta, P.O., John, G.E. and Henshaw, E.E. (2017) Prevalence of Listeria monocytogenes in Fresh and Raw Fish, Chicken and Beef. Journal of Advances in Microbiology, 3, 1-7. https://doi.org/10.9734/JAMB/2017/33132

[20] Akano, S.O., Moro, D.D., Deji-Agboola, A.M. and Oluwadun, A. (2013) Public Health Implication of Listeria Species and Other Bacteria Isolates of Abattoir Effluent in Lagos, Nigeria. International Research Journal of Microbiology, 4, 162-167.

[21] Onyemelukwe, G.C. and Lawande, R.V. (1982) Listeriosis in a Neonate and the Mother. Tropical and Geographical Medicine, 34, 87-89.

[22] Shindang, J., Shindang, C.O. and Ekwempu, A.I. (2013) Incidence of Listeria monocytogenes and Other Bacteria in Spontaneous Abortion Cases in Jos. Nigerian Journal of Biotechnology, 25, 18-22.

[23] Torvaldsen, S.L., Kurinczuk, J.J., Bower, C., Parsons, D.E. and Roberts, C.L. (1999) Listeria Awareness among New Mothers in Western Australia. Australian and New Zealand Journal of Public Health, 23, 362-367. https://doi.org/10.1111/j.1467-842X.1999.tb01276.x

[24] Bondarianzadeh, D., Yeatman, H. and Condon-Paoloni, D. (2007) Listeria Education in Pregnancy: Lost Opportunity for Health Professionals. Australian and New Zealand Journal of Public Health, 31, 468-474. https://doi.org/10.1111/j.1753-6405.2007.00120.x

[25] Taylor, M., Kelly, M., Noël, M., Brisdon, S., Berkowitz, J., Gustafson, L. and Galanis, E. (2012) Pregnant Women's Knowledge, Practices, and Needs Related to Food Safety and Listeriosis: A Study in British Columbia. Canadian Family Physician, 58, 1106-1112.

[26] Ogunmodede, F., Jones, J.L., Scheftel, J., Kirkland, E., Schulkin, J. and Lynfield, R. (2005) Listeriosis Prevention Knowledge among Pregnant Women in the USA. Infectious Diseases in Obstetrics and Gynecology, 13, 11-15. https://doi.org/10.1155/2005/734814

[27] Buffer, J.L., Medeiros, L.C., Kendall, P., Schroeder, M. and Sofos, J. (2012) Health Professionals' Knowledge and Understanding about Listeria monocytogenes Indicates a Need for Improved Professional Training. Journal of Food Protection, 75, 1310-1316. https://doi.org/10.4315/0362-028X.JFP-12-006

[28] Kirkham, C. and Berkowitz, J. (2010) Survey of British Columbia Practitioners' Knowledge of Risk Factors, Counselling Practices, and Learning Needs. Canadian Family Physician, 56, e158-e166.

[29] Axiom Research Company (2000) Physicians' Attitudes toward Food Safety Education. Final Report Prepared for International Food Information Council (IFIC), Axiom Research Company, Cambridge.

[30] Cates, S.C., Carter-Young, H.L., Conley, S. and O’Brien, B. (2004) Pregnant Women and Listeriosis: Preferred Educational Messages and Delivery Mechanisms. Journal of Nutrition Education and Behavior, 36, 121-127. https://doi.org/10.1016/S1499-4046(06)60148-6

[31] Mansouri-Najand, L., Kianpour, M., Sami, M. and Jajarmi, M. (2015) Prevalence of Listeria monocytogenes in Raw Milk in Kerman, Iran. Journal of Veterinary Research, Forum, 6, 223-226. 